\title{
Bacterial Counts in Spleen
}

Elías Barquero-Calvo ${ }^{1}$, Carlos Chacón-Díaz² ${ }^{2}$ Esteban Chaves-Olarte ${ }^{3}$ and Edgardo

$$
\text { Moreno }^{3^{*}}
$$

${ }^{1}$ Programa de Investigación en Enfermedades Tropicales, Escuela de Medicina Veterinaria, Universidad Nacional, Heredia, Costa Rica; ${ }^{2}$ Centro de Investigación en Enfermedades Tropicales, Facultad de Microbiología, Universidad de Costa Rica, San José, Costa Rica ; ${ }^{3}$ Centro de Investigación en Enfermedades Tropicales, Facultad de Microbiología, Universidad de Costa Rica, San José, Costa Rica

*For correspondence: emoreno@racsa.co.cr

[Abstract] Bacterial loads can be determined as colony forming units (CFU) at any point of the infection by culturing spleen homogenates on agar plates. This is a reliable method for comparing the kinetics of infection in various mouse strains, estimating the virulence of different bacterial mutants or isolates and for vaccine testing and vacine estandarization. Although this method has been designed to recover Brucella or Salmonella organisms from spleen, the procedure may be applicable for other bacteria such as Listeria and Mycobacterium as well as to count bacterial loads in other organs such as liver or lymph nodes.

\section{Materials and Reagents}

1. Sterile plastic bags, $30 \mathrm{~g}$ capacity $(\sim 30 \mathrm{ml})$ (Whirl-Pak ${ }^{\circledR}$ Write-On Bags) (Nasco, catalog number: B01067WA)

2. $70 \%$ Ethanol (Merck KgaA, Emsure ${ }^{\circledR}$, catalog number: 1009834000)

3. Latex examination gloves (Dermagrip ${ }^{\circledR}$, catalog number: D1402-14)

4. Pyrogen-free Type 1+ grade distilled water (Milli-Q Direct 8 and 16 Ultrapure Water System)

5. Dulbecco's Phosphate Buffered Saline (Gibco, catalog number: 21300-058)

6. Tween ${ }^{\circledR} 20$ (Sigma-Aldrich, catalog number: P5927)

7. Tryptone Soya Agar (Oxoid Limited, catalog number: CM0131) (see Recipes), or other media according to culture bacterial requirements

8. PBS $0.1 \%$ Tween 20 (see Recipes)

\section{Equipment}

1. 24-well plates, low binding cell (Sigma-Aldrich, catalog number: Z721077) 
2. Beaker $(100 \mathrm{ml})$

3. Glass alcohol burner (WHEATON, catalog number: WHE-237070)

4. Surgical instruments for mice (Mouse Surgical Kit) (Kent Scientific, model: INSMOUSEKIT)

5. Drigalski spatula (Thermo Fisher Scientific, catalog number: NC0242405)

6. Micropipettes $(10-100 \mu \mathrm{l}$ and $100-1,000 \mu \mathrm{l})$

7. Micropipette tips $(100 \mu \mathrm{l}$ and $1 \mathrm{ml})$

8. $1.5 \mathrm{ml}$ eppendorf tubes (Eppendorf, catalog number: 022363204)

9. Tuberculin plastic syringe $(1 \mathrm{ml})$ with $25-27 \mathrm{~g}$ needle gauge

10. Plastic petri dishes $(90 \times 15 \mathrm{~mm})$

11. Disposable medical plastic gloves (Lab Depot, catalog number: 266-P)

12. Small sharp scissors and forceps

13. Water purification system (Milli-Q Direct 8 and 16 Ultrapure Water System) (EMD Millipore, model: ZR0Q00800)

14. Bacterial incubator (Forma ${ }^{\circledR}$ Direct Heat $\mathrm{CO}_{2}$ Incubator) (Thermo Fisher Scientific, model: 310)

15. Autoclave (Yamato Scientific, model: SQ-500C)

16. Analytical balance electronic digital $( \pm 0.0001 \mathrm{~g})$

17. Laminar flow cabinet (Esco Global, Labculture ${ }^{\circledR}$ Class II, Type A2, model: LA2-3A2)

\section{Procedure}

A. Spleen extraction

1. Latex examination gloves should be used throughout the entire procedure.

2. Mice (Note 1) are infected by the corresponding via (e.g. intraperitoneally, intravenously, subcutaneously) using the recommended bacterial dose $\left(\right.$ e.g. $\left.10^{2}, 10^{3}, 10^{4}\right)$ depending on the assay and virulence of the bacteria employed. Intraperitoneal infection is carried out with tuberculin $1 \mathrm{cc}$ syringe, $25-27 \mathrm{~g}$ needle and maximum volume of $20 \mathrm{ml} / \mathrm{kg}$. http://www.procedureswithcare.org.uk/intraperitoneal-injection-in-the-mouse

3. Weight sterile plastic Whirl-Pak Bags (one per each mouse spleen) to the mg level.

4. Spleen must be obtained immediately after sacrifice (Note 2). Following the corresponding infection period (e.g. 3-15 days), mice are killed by cervical elongation keeping the appropriate ethical protocols and regulations (e.g. cervical dislocation, $\mathrm{CO}_{2}$ ) (Nagy et al., 2006) (Note 3).

5. After killing, spray the mouse exhaustively with $70 \%$ alcohol, and locate on a clean or sterile surface, within a safety vertical laminar flow hood. 
6. With small sharp scissors make a small cut into the skin below the belly bottom. Then open the entire abdominal cavity and cut the peritoneum and expose the spleen (situated in the left superior abdominal quadrant of the mouse) or the required organ, following $\begin{array}{llll}\text { recommended necropsy } & \text { (Covelli, } & 2013\end{array}$ http://eulep.pdn.cam.ac.uk/Necropsy of the Mouse/printable.php) (Note 4) (Figure 1).
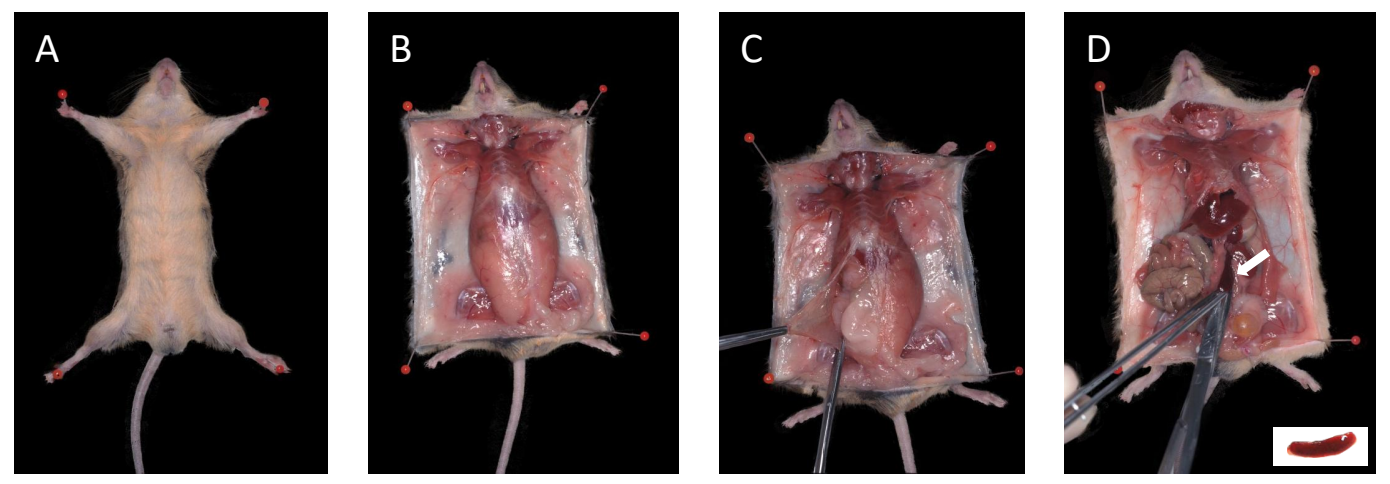

Figure 1. Spleen extraction indicating: A. position of the mouse for necropsy, B. opening of the mouse skin, C. opening of the abdominal wall and D. spleen extraction (pointed with white arrow). Photographs taken from Covelli, 2013. For details, this work may be consulted at:

http://eulep.pdn.cam.ac.uk/Necropsy of the Mouse/printable.php (date consulted: 09/30/2013).

7. Use small forceps to hold the spleen and then cut the hilum together with the gastrosplenic ligament to remove the spleen and locate inside a pre-weighted sterile plastic Whirl-Pak Bag (Note 5) (Figure 1).

8. Weight the spleens inside the bags using a 4 digit scale balance. To obtain the spleen weight, subtract the value of the empty preweighted plastic bag.

B. Spleen homogenization

1. Add 9 parts of PBS containing $0.1 \%$ Tween 20 per $\mathrm{g}$ of spleen (dilution $1: 10$ ), assuming that the volume of $1 \mathrm{~g}$ of spleen corresponds to $1 \mathrm{ml}$ of PBS (e.g. 0.5 grams of spleen and $4.5 \mathrm{ml}$ of PBS $0.1 \%$ Tween 20 ).

Note: Homogenization is easier if a small volume is used at the beginning of the homogenization procedure and then, the remaining volume is completed to reach 1:10 dilution.

2. Spleen homogenization is proficiently carried out by squeezing the organ inside bag by hand. 
Note: In order to release the intracellular bacteria, spleen cells are disrupted by squeezing the spleen tissue in PBS containing 0.1\% Tween 20.

3. After homogenization of the samples, and depending on expected bacterial spleen colonization, decimal (or the required) dilutions are performed with 1x PBS (on $1.5 \mathrm{ml}$ eppendorf tubes or 24 well plates).

Note: Open the plastic bag carefully and widely (using steel wires) to avoid contamination of the pipette. For infections using $1 \times 10^{6} \mathrm{CFU}$ of bacteria and ranging from 1-30 days, plate $10^{2}-10^{5}$ dilutions.

C. Plating

1. Two plating methods are suggested:

Method A

Dispense three separate $20 \mu \mathrm{l}$ drops of each dilution on Tryptone Soya Agar (or the recommended media for growing the tested bacterium) plates using two plates per sample (Figure 2A). Then, let the drops to be absorbed in the agar surface (do not spread out the drops) prior incubation (5-10 minutes).

Method B

Dispense one $100 \mu \mathrm{l}$ in each agar plate and distribute the sample with a sterile Drigalski spatula until the inoculum is fully dispersed on the agar surface using two plates per sample (Figure 2B).

Notes:

a. Method $A$ is quicker and fewer agar plates are required since four dilutions can be positioned on each plate. In addition, up to three drops can be put for each dilution, lessening counting errors. A minimum of 500 bacteria per $g$ of spleen can be detected if $10^{1}$ dilution is plated.

b. Method $B$ is slower and increases plate consuming but is more sensitive when low bacterial loads are expected. Colony counting is easier since an entire plate is used per dilution. A minimum of 100 bacteria per $g$ of spleen can be detected if $10^{1}$ dilution is plated.

2. Plates are incubated under the required conditions for the bacterial strain (e.g. $37{ }^{\circ} \mathrm{C}$ under $5 \% \mathrm{CO}_{2}$ atmosphere for 2-3 days) until colony forming units (CFUs) are evident.

3. Count CFU in the various dilutions. Only use the plates (and the corresponding dilutions) in which separate colonies are obtained (10-30 CFUs in Figure 2A or 30-300 CFUs in Figure 2B).

4. Calculate spleen bacterial loads by multiplying CFUs to the corresponding dilution and by 50 in method $A$ or by 10 in method $B$, respectively. 
5. CFUs means can be calculated either by CFUs/spleen (total CFUs recovered) or alternatively by CFUs/gram of spleen (total CFUs recovered divided by total grams of spleen). While the first method does not take into consideration spleen inflammation (size), the second method corrects for spleen swelling. In either case, it is always recommended to plot the spleen weight in a separate graph.

A

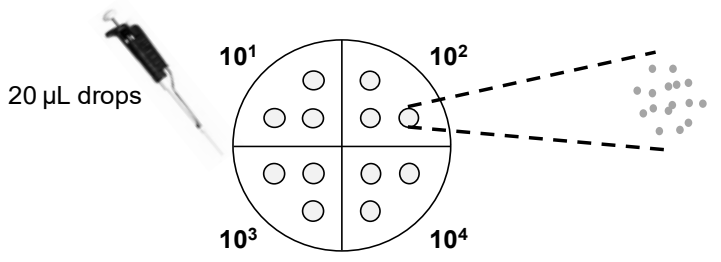

B

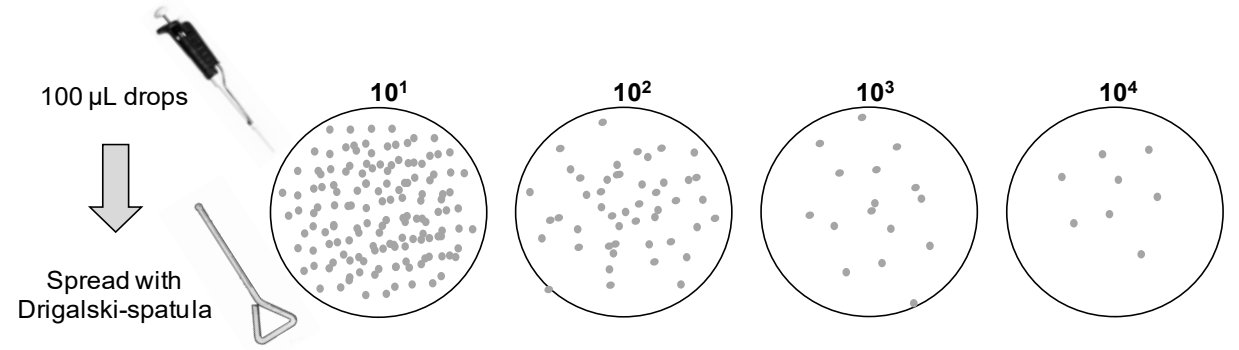

Figure 2. Sample plating methods

\section{$\underline{\text { Notes }}$}

1. Preferably, female mice (male mice from different litters have the tendency to fight) with weights ranging between 18-22 grams. Weight/age ratio varies depending upon the strain of mice. Older mice have the tendency of display more weight variation. Differences in weights or ages should be avoided. It is recommended to work with groups of four mice in tandem. Mice should be in good health conditions before the experiment. In the case of using immunosuppressed mice, it is recommended to include a group of non-infected negative control mice to check for previously acquired bacterial or yeast infections.

2. Bacterial counts in organs after natural death or after a protracted period of time are not recommended, due to microorganism contamination during the process of tissue decay.

3. Other methods used for sacrifice are $\mathrm{CO}_{2}$ affixation or overdose of anesthesia with components such as isoflurane (inhaled $>15 \%$ ) or propofol (intravenously $>50 \mathrm{mg} / \mathrm{kg}$ ).

4. Avoid the skin hair of the mouse to become in contact with the peritoneal cavity.

5. The spleen is easily detached without abundant hemorrhage. Surgical instruments must be sterilized with alcohol and flamed prior spleen manipulation to avoid contamination. External fat should be removed from the spleen to avoid extra weight errors. 


\section{$\underline{\text { Recipes }}$}

1. Tryptone Soya Agar

Suspend 40 grams of medium in $1 \mathrm{~L}$ Pyrogen-free Type 1+ grade distilled water Heat with frequent agitation and boil for $1 \mathrm{~min}$ to completely dissolve the medium Autoclave at $121^{\circ} \mathrm{C}$ for $15 \mathrm{~min}$

2. PBS $0.1 \%$ Tween 20

Dissolve the following in $800 \mathrm{ml}$ Pyrogen-free Type 1+ grade distilled water $\mathrm{H}_{2} \mathrm{O}$

$8 \mathrm{~g}$ of $\mathrm{NaCl}$

$0.2 \mathrm{~g}$ of $\mathrm{KCl}$

$1.44 \mathrm{~g}$ of $\mathrm{Na}_{2} \mathrm{HPO}_{4}$

$0.24 \mathrm{~g}$ of $\mathrm{KH}_{2} \mathrm{PO}_{4}$

$1 \mathrm{ml}$ Tween 20

Adjust $\mathrm{pH}$ to 7.4

Adjust volume to $1 \mathrm{~L}$ with additional Pyrogen-free Type 1+ grade distilled water $\mathrm{H}_{2} \mathrm{O}$ Sterilize by autoclaving

\section{Acknowledgments}

We thank María-Jesús Grilló for helping in the standardization of this technique. This protocol was adapted from the following original published papers Barquero-Calvo et al. (2007) and Nagy et al. (2007), and from Covelli (2013). This work was funded by grants from FIDA-2006, FS-CONARE (UNA/UCR), MICIT/CONICIT (FI-487-09), 8-N-2005 and B/3456-1 (NeTropica), B/3456-2 (IFS), AGL2004-01162/GAN (Spain), CNRS and INSERM (France) and MASTERSWITCH projects (European Communities).

\section{$\underline{\text { References }}$}

1. Barquero-Calvo, E., Chaves-Olarte, E., Weiss, D. S., Guzman-Verri, C., Chacon-Diaz, C., Rucavado, A., Moriyon, I. and Moreno, E. (2007). Brucella abortus uses a stealthy strategy to avoid activation of the innate immune system during the onset of infection. PLoS One 2(7): e631.

2. Covelli, V. (2013). Guide to the Necropsy of the Mouse. http://eulep.pdn.cam.ac.uk/Necropsy of the Mouse/printable.php.

3. Nagy, A., Gertsenstein, M., Vintersten, K. and Behringer, R. (2006). Quick and humane sacrifice of a mouse by cervical dislocation. CSH Protoc 2006(1). 